\title{
Fracionamento e germinação de sementes de Eugenia involucrata
}

\author{
Cutting and germination of Eugenia involucrata seeds
}

\section{Juliano Pereira Gomes*, Luciana Magda de Oliveira, Karina Montibeller da Silva, Paula Iaschitzki Ferreira e Helen Michels Dacoregio}

Recebido em 24/02/2016 / Aceito em 18/05/2016

\section{RESUMO}

Objetivou-se verificar a eficiência do método de fracionamento em sementes de Eugenia involucrata na formação de plântulas, como forma de maximização de lotes para a produção de mudas. Sementes de $E$. involucrata foram submetidas aos tratamentos: a) Controle (sementes sem fracionamento), b) Sementes fracionadas transversalmente, com e sem hilo e c) Sementes fracionadas longitudinalmente, com e sem hilo, e, em seguida, à germinação em substrato rolo de papel tipo germitest, sob temperatura de $25{ }^{\circ} \mathrm{C}$ e luz branca constante, com quatro repetições de 25 sementes ou frações de sementes. Foram calculados a porcentagem de propágulos com capacidade de produzir plântulas normais (porcentagem de germinação) e a velocidade de germinação (índice de velocidade de germinação - IVG). As sementes sem fracionamento (controle) apresentaram maior porcentagem $(72 \%)$ e velocidade de germinação $(\mathrm{IVG}=0,64)$. A utilização de fracionamento não é eficiente para maximização de lotes de sementes de E. involucrata, pois a germinação foi diretamente afetada.

PALAVRAS-CHAVE: propágulos, maximização da germinação, produção de mudas.

\section{ABSTRACT}

The objective of this study is to verify the cutting efficiency of Eugenia involucrata seeds in seedling formation, as a way to maximize seed lots for sapling production. E. involucrata seeds were submitted to the following treatments: a) Control (uncutting seeds), b) Seeds transversely cut, with or without hilum, c) Seeds longitudinally cut, with and without hilum and germinated afterwards on germitest paper roll substrate at a temperature of $25^{\circ} \mathrm{C}$ and constant white light, with four repetitions of 25 seeds or seed fractions. The percentage of propagules with capacity to produce normal seedlings (the germination percentage) and germination speed (the Speed of Germination Index) were calculated. The uncut seeds (control) showed a higher germination percentage $(72 \%)$ and speed (SGI $=0.64)$. The use of seed fractions was not considered an efficient method for maximizing E. involucrata seed lots, since germination was directly affected.

KEYWORDS: propagules, maximizing germination, seedling production.

\section{INTRODUÇÃO}

A produção de mudas de essências florestais, tanto para recomposição de áreas alteradas (SANTARELLI 2004; BRANCALION et al. 2010) como para produção comercial de frutos (WILLERDING \& OLIVEIRA 2005), impulsiona o mercado em busca por espécies arbóreas nativas potenciais (MARTINS 2011).

Dentre as espécies nativas que possuem demanda em viveiros florestais, destaca-se Eugenia involucrata DC. (TONETTO et al. 2013), a qual é popularmente conhecida como cereja ou cerejeira do mato. Trata-se de uma Myrtaceae com ocorrência natural nas regiões Sul e Sudeste do Brasil (SOBRAL et al. 2016), onde é pouco difundida em forma de plantios comercias e pomares domésticos (LORENZI et al. 2006; SOUZA \& LORENZI 2008).

Esta espécie apresenta frutos carnosos e de sabor exótico, os quais são indicados para processamento de doces, geleias, licores ou para consumo in natura (LORENZI et al. 2006; CARVALHO 2008). A atratividade dos frutos, em função dos recursos energéticos, coloração vibrante

Universidade do Estado de Santa Catarina, Lages, SC, Brasil.

*Autor para correspondência <julianopgomes@yahoo.com.br> 
e componentes nutracêuticos, enaltece a espécie para compor programas de recuperação de áreas alteradas, paisagismo, arborização de áreas urbanas (LORENZI et al. 2006) e, principalmente, para formação de populações comerciais. E. involucrata também se destaca pelas suas propriedades medicinais.

Em ambientes naturais, esta Myrtaceae ocorre em baixa densidade (HACK et al. 2005), fato que requer estudos sobre fenologia, biologia reprodutiva, dispersão e, especialmente, obtenção de material propagativo de qualidade e em quantidade satisfatória. A limitada produção de sementes pode ter relação com a restrita abundância de matrizes em remanescentes florestais, bem como, o reduzido número de sementes, que segundo CARVALHO (2008), a produção média é de três sementes por fruto. A intolerância a dessecação também restringe a produção de mudas de $E$. involucrata (WIELEWICKI et al. 2006; DELGADO \& BARBEDO 2007), pois o período de manutenção da viabilidade de suas sementes é relativamente curto.

Trabalhos realizados em sementes de Myrtaceae, por SILVA et al. (2003) e SILVA et al. (2005) utilizaram a técnica de fracionamento de sementes para averiguar o potencial de emissão de múltiplas plântulas por diásporo. Em meio às possibilidades de se obter maior número de mudas por propágulo, que poderiam suprir a demanda por mudas de cereja do mato, destacam-se as alterações reprodutivas, como, por exemplo, a apomixia, polisporia (bisporia e tetrasporia) e poliembrionia (CARMAN 1997). Portanto, pelo conjunto de fatores influentes sobre a disponibilidade de mudas desta espécie, é imprescindível pesquisas que forneçam adequados métodos de propagação, possibilitando a maximização de lotes de sementes.

De acordo com o exposto, objetivou-se verificar a eficiência do método de fracionamento de propágulos de E. involucrata na formação de plântulas, como forma de maximização de lotes de sementes para a produção de mudas.

\section{MATERIAL E MÉTODOS}

A colheita de frutos maduros, de coloração arroxeada, de Eugenia involucrata foi realizada em seis matrizes, localizadas no município de Correia Pinto, SC. Após a colheita, as sementes foram extraídas manualmente dos frutos e submetidas aos testes.

Foram testados os tratamentos Controle (sementes sem fracionamento), Sementes fracionadas transversalmente com a presença de hilo, Sementes fracionadas transversalmente sem hilo, Sementes fracionadas longitudinalmente com hilo e Sementes fracionadas longitudinalmente sem hilo. O fracionamento dos propágulos foi realizado utilizando-se um bisturi, o qual possibilitou melhor precisão nos cortes e redução de danos nos tecidos.

As sementes, inteiras e fracionadas, foram colocadas para germinar em substrato rolo de papel tipo Germitest, sob temperatura de $25{ }^{\circ} \mathrm{C}$ e luz branca constante, em quatro repetições de 25 sementes ou frações de sementes por tratamento. A primeira avaliação do teste de germinação foi realizada cinco dias após a instalação do teste, e as demais, a cada dois dias, facilitando o acompanhamento de todas as etapas do processo de germinação. Foi avaliado o número de sementes que originaram plântulas normais (plântulas com sistema radicular presente e sem defeitos, e epicótilo com folhas visíveis). Este número foi considerado para o cálculo da porcentagem de propágulos com capacidade de produzir plântulas normais. Foi calculada também a velocidade de germinação, por meio do índice de velocidade de germinação (IVG).

Os resultados foram submetidos à análise de variância e as médias foram comparadas pelo teste de Tukey, a $1 \%$ de probabilidade.

\section{RESULTADOS E DISCUSSÃO}

Os resultados de porcentagem e velocidade de germinação (IVG) apresentaram diferenças significativas quanto aos tratamentos utilizados (Tabela 1). Em relação ao IVG, o tratamento controle (sem fracionamento) apresentou o melhor resultado quanto à capacidade de formar plântulas normais em menor período, divergindo dos demais, sobretudo nos tratamentos em que as frações não permaneceram com hilo. $\mathrm{O}$ valor obtido no tratamento controle é semelhante ao observado por SILVA et al. (2003), onde o índice de velocidade de germinação foi de 0,63 para sementes intactas de E. involucrata (Tabela 1).

As sementes sem fracionamento (controle) apresentaram maior capacidade germinativa, das quais, $72 \%$ foram capazes de produzir plântulas normais (Tabela 1). A maior capacidade de sementes inteiras germinarem ocorreu, provavelmente, pela maior quantidade de reservas acumuladas, o que aumenta a probabilidade de sucesso no estabelecimento de 
Tabela 1 - Porcentagem de germinação e índice de velocidade de germinação (IVG) de sementes de Eugenia involucrata submetidas a diferentes tratamentos de fracionamento.

Table 1 - Germination percentage and speed index of germination (IVG) of Eugenia involucrata seeds submitted to different treatments of fractionation.

\begin{tabular}{lll}
\hline Tratamentos & Germinação (\%) & IVG \\
\hline Controle & $72 \mathrm{~A}$ & $0,64 \mathrm{~A}$ \\
Transversal com Hilo & $36 \mathrm{~B}$ & $0,47 \mathrm{~B}$ \\
Longitudinal com Hilo & $24 \mathrm{C}$ & $0,43 \mathrm{~B}$ \\
Transversal sem Hilo & $4 \mathrm{D}$ & $0,19 \mathrm{C}$ \\
Longitudinal sem Hilo & $4 \mathrm{D}$ & $0,16 \mathrm{C}$ \\
\hline CV $(\%)$ & 18,07 & 14,01 \\
F & 123,75 & 96,0 \\
\hline
\end{tabular}

Médias seguidas pela mesma letra, na coluna, não diferem entre si pelo teste de Tukey ao nível de 1\%.

plântulas. Em relação ao percentual de germinação obtido, foi verificado que os resultados ficaram abaixo dos valores frequentemente encontrados em sementes de Eugenia spp., as quais geralmente apresentam germinação acima de 90\% (SILVA et al. 2005; DELGADO \& BARBEDO 2007). Possivelmente este fato esteja vinculado a fatores que reduzem a qualidade do lote, como por exemplo, déficit hídrico durante a formação do embrião. A alta taxa de germinação caracteriza o potencial das Myrtaceae em formar banco de plântulas, pois geralmente possuem sementes recalcitrantes, e necessitam se estabelecer antes da desidratação, sendo consideradas espécies clímax.

Apesar do fracionamento mantendo hilo demonstrar razoável capacidade de desenvolvimento de plântulas normais (Figura 1), o processo de fracionamento afetou diretamente o potencial germinativo, em relação ao tratamento controle (Tabela 1). Ao contrário desses resultados, SILVA et al. (2005) relataram que frações de sementes de E. involucrata apresentaram alto potencial de regeneração, onde o somatório dos valores de germinação das duas metades superou os $100 \%$. ANJOS \& FERRAZ (1999) também descreveram que sementes de Eugenia stipitata Mc Vaugh dispõem elevada capacidade regenerativa após algum dano.

JOLY (2002) relata sobre a capacidade de algumas Myrtaceae produzirem vários embriões, pois há presença de embriões adventícios nas sementes, o que confere a possibilidade de formar plântulas normais. Dos vários embriões formados, um obrigatoriamente será originado de fecundação cruzada e os demais com características geneticamente idênticas à planta da qual se originaram (ARON et al. 1998). Tais embriões apresentam a mesma carga genética da matriz mãe pelo crescimento das células somáticas formadoras do tecido nucelar na semente. A presença de poliembrionia em sementes de espécies de Eugenia, com embriões nucelares, foi observada em E. cumini (L.) Druce, E. hookeri Steud, E. jambolana, E. jambos L., E. malaccensis L. e E. caryophyllifolium (Lam.) DC (CORNER 1976), demonstrando o potencial do gênero. A capacidade de algumas espécies vegetais em produzir sementes poliembriônicas tratase de um importante instrumento para fruticultores de espécies nativas, pois os indivíduos obtidos por meio de embriões adventícios são considerados clones e com isto é possível selecionar características mais viáveis para propagação.

As frações sem presença de hilo, independentemente da forma de fracionamento (longitudinal ou transversal), demonstraram reduzida capacidade de formação de plântulas normais (4\%). De maneira geral, ocorreu somente o desenvolvimento de raízes múltiplas (Figura 2). A formação de várias raízes em sementes fracionadas (Figura $2 \mathrm{~F}$ ), também foi verificada em sementes de E. pyriformis nos estudos desenvolvidos por SILVA et al. (2003) e AMADOR \& BARBEDO (2011). AMADOR \& BARBEDO (2011) observaram que o surgimento de raízes e plântulas após o fracionamento ocorre devido à formação de novos tecidos e não, em função do desenvolvimento de embriões diferenciados já existentes. 


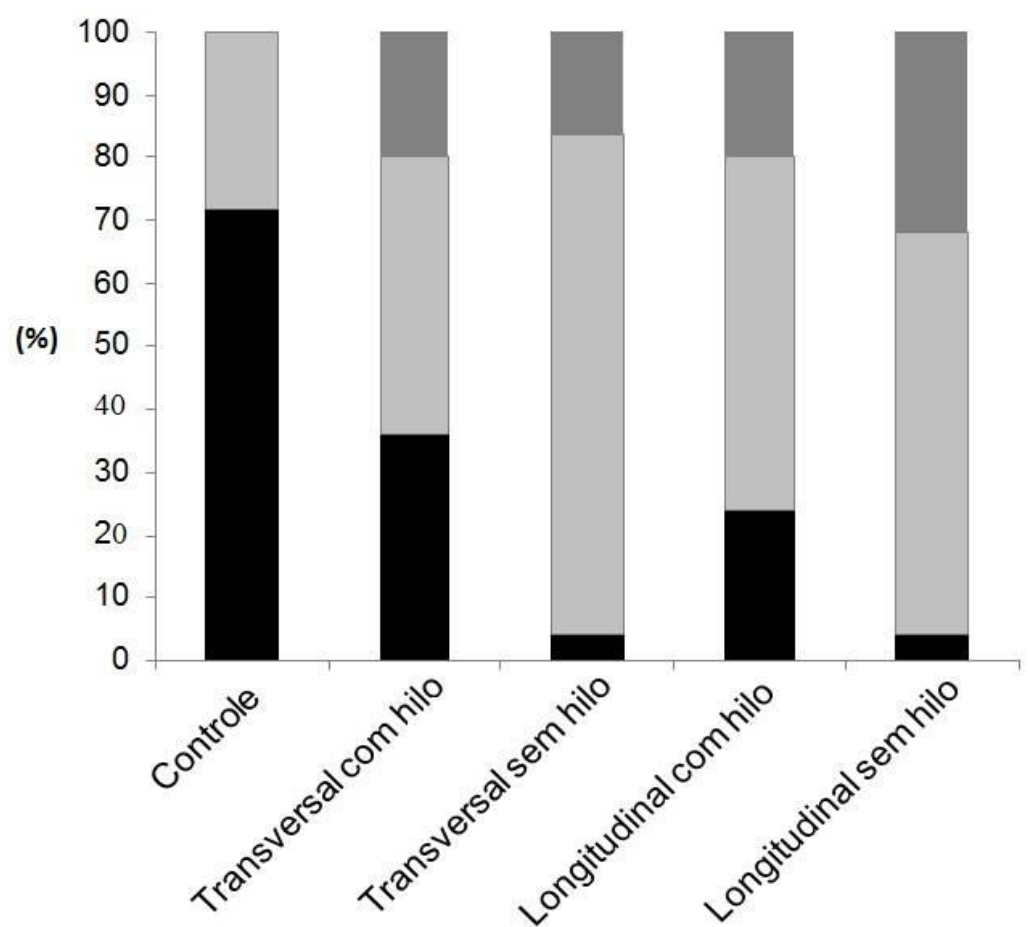

Mortas

$\square$ Plântulas Anormais

-Plântulas Normais

Figura 1 - Porcentagem de plântulas normais, anormais e sementes mortas obtidas no teste de germinação de sementes de Eugenia involucrata submetidas aos tratamentos controle, corte transversal com hilo e sem hilo, longitudinal com hilo e sem hilo.

Figure 1 - Percentage of normal and abnormal seedlings and dead seeds obtained in the germination test of Eugenia involucrata submitted to control, section transversely with hilum and without hilum, longitudinal with hilum and without hilum treatments.

Segundo KOZLOWSKI \& PALLARDY (1997), há a possibilidade de ocorrer somente um embrião em sementes de E. involucrata, mas o mesmo pode se subdividir e formar dois núcleos ou dois sacos embrionários. Já GURGEL \& SOUBIHE SOBRINHO (1951) relataram que a espécie apresenta apenas um embrião, e que, se ocorrer a germinação de duas ou mais plântulas, pode ser em função da poliembrionia falsa. Este fenômeno é descrito por MENDES (1994) como a aparente ocorrência de vários embriões em uma semente, no entanto, há apenas um embrião bifurcado, ou ainda, dois ou mais embriões localizados em endospermas separados, ou seja, duas ou mais sementes unidas, dando aspecto de apenas uma.

A protrusão radicular iniciou no $9^{\circ}$ dia para sementes inteiras. Para as frações transversais com e sem hilo, e longitudinais com e sem hilo, a germinação começou, respectivamente, aos $10^{\circ}, 18^{\circ}, 12^{\circ}$ e $14^{\circ}$ dias após a instalação do teste. Algumas frações sem presença de hilo, independente do método de fracionamento, iniciaram o processo de protrusão radicular 30 dias após a montagem do experimento, e geralmente não dispunham de bom desenvolvimento da estrutura radicular (Figura 2F, 2E).

Embora as frações de sementes com hilo tenham germinado (Figura 2A), o período do processo germinativo até a finalização do teste é muito prolongado, em torno de 90 dias, denotando uma germinação lenta, comparado ao tratamento controle (sem fracionamento), assim como, houve formação de plântulas com alterações morfológicas (Figura 2B). Apesar da não uniformidade do processo germinativo, as sementes fracionadas com presença do hilo demonstraram capacidade regenerativa (Figura 2A, 2C, 2D), o que provavelmente ocorre em virtude da elevada quantidade de reservas disponíveis, que podem ser utilizadas para construção de novas células e tecidos. Esta aptidão caracteriza uma possível estratégia de escape da espécie quando submetida a condições adversas. $\mathrm{O}$ maior potencial germinativo das frações com hilo, também pode ser resultado do posicionamento do embrião, já que o mesmo está justaposto a região morfológica do hilo. 

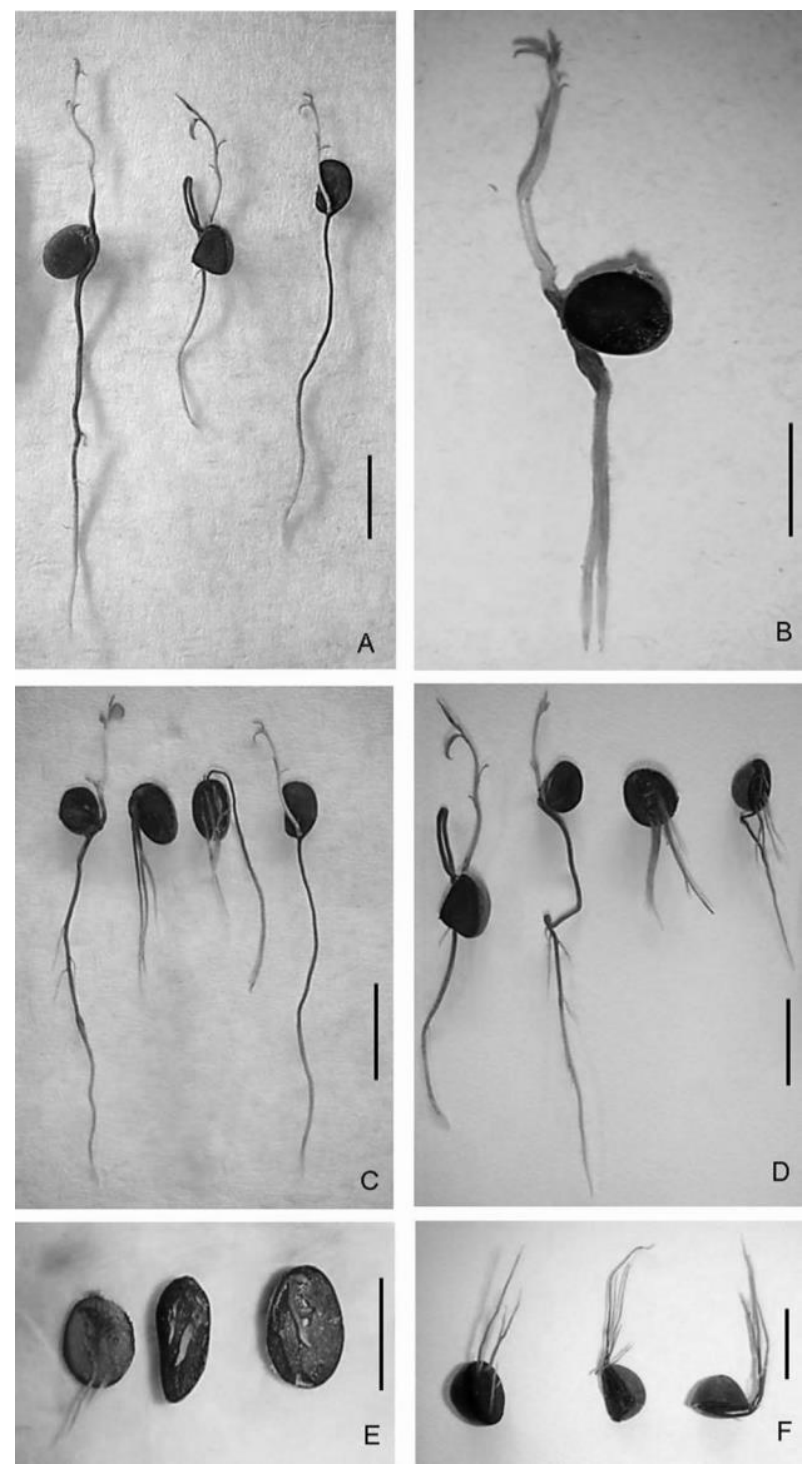

Figura 2 - Germinação de sementes e frações de sementes de Eugenia involucrata DC. A. Plântulas normais de sementes submetidas aos tratamentos (controle, transversal com hilo e longitudinal com hilo); B. Plântula anormal com raiz pivotante bifurcada originada de fração longitudinal com hilo; C. Plântulas normais (fração com hilo) e emissão de raízes múltiplas (fração sem hilo) em sementes fracionadas longitudinalmente; D. Plântulas normais (fração com hilo) e emissão de raízes múltiplas (fração sem hilo) em sementes fracionadas transversalmente; E. Frações com início de formação de raízes múltiplas; F. Formação de raízes múltiplas em sementes fracionadas sem presença de hilo.

Figure 2 -Seed germination and seed fractions of Eugenia involucrata DC. A. Normal seedlings submitted to seed treatments (control, transversely with hilum and longitudinal without hilum); B. Normal seedlings with pivoting bifurcated roots originated from longitudinal fraction with hilum; $C$. Normal seedlings (with hilum) and multiple roots (without hilum) emission in seeds longitudinally fractionated; D. Normal seedlings (with hilum) and multiple roots (without hilum) emission in seeds transversely fractionated seeds; E. Fractions beginning the multiple roots development; F. Development of multiple roots in seeds without the fractional hilum presence. 


\section{CONCLUSÃO}

De modo geral, os resultados demonstraram que a utilização de fracionamento não é um eficiente método para aumentar o número de plântulas por sementes, assim como, as frações de semente sem hilo que germinaram geralmente apresentavam plântulas anormais. Foi notável que nenhum dos tratamentos superou os valores obtidos pela testemunha, pois mesmo somados todos os valores dos quatro tratamentos $(68 \%)$ não alcançaram os resultados obtidos pelos propágulos inteiros (72\%) (Tabela 1). Portanto, o fracionamento não possibilitou maior porcentagem e velocidade de germinação, pois independente do método, não houve eficiência, além de demandar maior mão de obra.

\section{REFERÊNCIAS}

AMADOR TS \& BARBEDO CJ. 2011. Potencial de inibição da regeneração de raízes e plântulas em sementes germinantes de Eugenia pyriformis. Pesquisa Agropecuária Brasileira 46: 814-821.

ANJOS AMG \& FERRAZ IDK. 1999. Morfologia, germinação e teor de água das sementes de araçá-boi (Eugenia stipitata ssp. sororia). Acta Amazonica 29: 337348.

ARON Y et al. 1998. Polyembryony in mango (Mangifera indica L.) is controlled by a single dominant gene. Hortscience 33: 1241-1242.

BRANCALION PHS et al. 2010. Instrumentos Legais podem Contribuir para a Restauração de Florestas Tropicais Biodiversas. Revista Árvore 34: 455-470.

CARMAN JG. 1997. Asynchronous expression of duplicate genes in angiosperms may cause apomixis, bispory, tetraspory, and polyembryony. Biological Journal of the Linnean Society 61: 51-94.

CARVALHO PER. 2008. Espécies arbóreas brasileiras: recomendações silviculturais, potencialidade e uso da madeira. Brasília: Embrapa Informações Tecnológicas. 593p.

CORNER EJH. 1976. The seeds of dicotyledons. Cambridge: Cambridge University Press. 558p.

DELGADO LF \& BARBEDO CJ. 2007. Tolerância à dessecação de sementes de espécies de Eugenia. Pesquisa Agropecuária Brasileira 42: 265-272.

GURGEL JTA \& SOUBIHE SOBRINHO J. 1951. Poliembronia em mirtáceas frutíferas. Bragantia 11: 141163.

HACK $\mathrm{C}$ et al. 2005. Análise fitossociológica de um fragmento de floresta estacional decidual no município de Jaguari, RS. Ciência Rural 35: 1083-1091.

JOLY AB 2002. Botânica: Introdução à taxonomia vegetal.
13. ed. São Paulo: Companhia Editora Nacional. 777p.

KOZLOWSKI TT \& PALLARDY SG 1997. Physiology of Woody Plants. San Diego: Academic Press. 411p.

LORENZI $\mathrm{H}$ et al. 2006. Frutas Brasileiras e exóticas cultivadas: de consumo in natura. Nova Odessa: Instituto Plantarum. 640p.

MARTINS RB 2011. Diagnóstico de produtores de mudas florestais nativas do Estado de São Paulo. São Paulo: Secretaria de Estado do Meio Ambiente. 154p. (Relatório Analítico).

MENDES AJT. 1944. Observações citológicas em Coffea: VIII - poliembrionia. Bragantia 4: 693-708.

SANTARELLI EG. 2004. Produção de mudas de espécies nativas. In: RODRIGUES, R.R.; LEITÃO FILHO, H.F. (Ed.). Matas ciliares: conservação e recuperação. 3.ed. São Paulo: Edusp/Fapesp. p.313-318.

SILVA CV et al. 2005. Fracionamento e germinação de sementes de Eugenia. Revista Brasileira de Sementes 27: 86-92.

SILVA CV et al. 2003. Fracionamento e germinação de sementes de uvaia (Eugenia pyriformis Cambess. Myrtaceae). Revista Brasileira de Botânica 26: 213-221.

SOBRAL $M$ et al. 2016. Myrtaceae in Lista de Espécies da Flora do Brasil - Jardim Botânico do Rio de Janeiro. Disponível em:floradobrasil.jbrj.gov.br/jabot/floradobrasil/ FB10419 Acesso em: 10 jun. 2016.

SOUZA VC \& LORENZI H. 2008. Botânica Sistemática: Guia ilustrado para a identificação das famílias de Fanerógamas nativas e exóticas no Brasil, baseado em APG II. 2. ed. Nova Odessa: Instituto Plantarum. 704p.

TONETTO TS et al. 2013. Dinâmica populacional e produção de sementes de Eugenia involucrata na floresta estacional subtropical. Floresta e Ambiente 20: 62-69. WIELEWICKI AP et al. 2006. Proposta de padrões de germinação e teor de água para sementes de algumas espécies florestais presentes na região sul do Brasil. Revista Brasileira de Sementes 28: 191-197.

WILLERDING AL \& OLIVEIRA LA. 2005. Diagnóstico de um projeto de enriquecimento florestal na Comunidade do Brasileirinho, Manaus, Amazonas. Acta Amazonica 35: 421-426. 